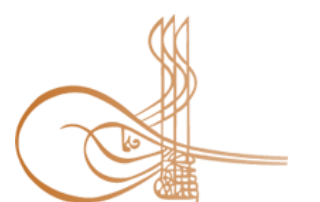

www.turkishstudies.net/economy
Turkish Studies - Economics, Finance, Politics

eISSN: $2667-5625$

Research Article / Araștırma Makalesi

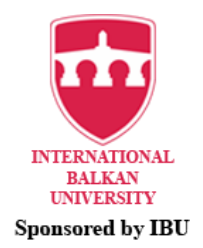

Sponsored by IBU

\title{
Katılım Bankacılığında İnovatif ve Dijital Çözümler: Türkiye İçin Bir Model Önerisi
}

Innovative and Digital Solutions in Participation Banking: A Model Proposal for Turkey

\author{
Zeliha Tekin*
}

\begin{abstract}
Digitalization, a means of making life easier for banks to provide innovative and fast services to their customers, is also closely related to participation banking, an actor of the interest-free finance sector in the era of Industry 4.0. API markets, cyber security, data analytics and big data solutions, artificial intelligencebased chatbots and blockchain applications, cloud technologies, augmented and virtual reality are among the most important issues in this digitalization journey for participation banks. Therefore, the aim of this study is to determine which technology applications the innovative digital solutions are based on in participation banking and to determine what advantages they provide to participation banks and their customers in Turkey. For this purpose, the news published in the national press in 2019 were searched in the Google search engine and 150 news stories which includes the words "Innovation in Interest-free Financial Banking" and "Participation Banking and Digitalization" were framed according to the purpose of the study and the websites of 6 banks (Albaraka Türk, Kuveyt Türk, Türkiye Emlak Katılım, Ziraat Katılım, Vakıf Katılım, Türkiye Finans Katılım) in Turkey that are the most mentioned in the news content and carry their technological infrastructure to digital channels by investing in innovative / digital products, services and platforms were examined and content analysis which is a qualitative research method was carried out. In the literature part of the study, articles related to innovative digital applications in participation banking were used; current situation analysis / check-up was made and innovative-digital examples of the best practices of participation banks in Turkey are given. A model called Digital Banking habitat has been established in Turkey's participation banking based on the findings obtained from the content analysis and starting from the suggestions that will be beneficial for our country in terms of digitalization in the field of participation banking. The results of the study showed that the innovative digital applications of participation banks included technology use such as Artificial Intelligence and Cloud Technology, and increased internet/mobile/digital banking operations. It has been observed that these applications have created brand value, better communication with customers, meeting customer expectations, leading to an increase in performance and efficiency, providing a fast response to customers, saving time, increasing their competitive power and number of customers with different-qualityinnovative-fast service.
\end{abstract}

Structured Abstract: Introduction Participation Banking, also known as Islamic Banking and Interest-Free Banking, which operates in accordance with Islamic rules, is preferred by Muslim investors who want to evaluate their savings in the field of finance without interest and who are especially religiously sensitive, is a banking model that develops under the leadership of countries such as Saudi Arabia, United Arab Emirates,

\footnotetext{
* Doç. Dr. Muş Alparslan Üniversitesi, İktisadi ve İdari Bilimler Fakültesi, Uluslararası Ticaret ve İşletmecilik Bölümü Assoc. Prof. Dr. Mus Alparslan University, Faculty of Economics and Administrative Sciences, Department of International Trade and Business 
Qatar, Bahrain, Malaysia, Kuwait, Indonesia, Dubai. In this context, the answers to the following questions were sought in the study:

- What innovative digital applications do participation banks in Turkey use?

- What are the benefits of innovative digital applications used by participation banks?

This study was needed and made it unique because there were not many academic studies on determining innovative and digital applications in Participation Banking, and what performance or success indicators these applications in participation banking had, and the studies carried out earlier have covered the issue superficially.

\section{Conceptual Framework}

Participation banking, where all banking transactions are carried out without interest and away from risky speculative structure, is a banking model that provides loans through current and participation accounts, collects funds, and distributes profits and losses fairly by adhering to equity. In this model, banks share with their customers the profits and losses resulting from the evaluation of the funds they collect from their customers on the basis of USD, EUR and TL in the field of industry and commerce (products, semi-products or raw materials, machinery, equipment, real estate that the industry and trade need are provided through this method) within the framework of interest-free financing rules. Products that are harmful to health such as games of chance, weapons, alcohol, tobacco cannot be subject to participation banking transaction (www.ttbb.org.tr, 2019). The objectives of the participation banks are as follows:

- Application of Islamic principles to economic life,

- $\quad$ Creating employment by directing savings to direct investments,

- Establishing a balanced financial system,

- Ensuring that banking transactions and services are carried out in line with Islamic principles,

- $\quad$ Being able to live with other banks, taking advantage of profit opportunities for success.

\section{Research Methodology}

The expressions "Innovation in Islamic Finance Banking" and "Participation Banking and Digitalization" have been scanned in the Google search engine and 150 news / articles overlapping for the purpose of research have been framed and the websites of 6 banks (Albaraka Türk, Kuveyt Türk, Türkiye Emlak Katılım, Ziraat Katılım, Vakıf Katılım, Türkiye Finans Katılım) in Turkey that are the most mentioned in the news content and carry their technological infrastructure to digital channels by investing in innovative / digital products, services and platforms were examined and content analysis was carried out. Therefore, Albaraka Türk, Kuveyt Türk, Türkiye Emlak Katılım, Ziraat Katılım, Vakıf Katılım and Türkiye Finans Katılım Banks formed the sample of the research. The innovative-digital applications offered by participation banks to their customers and the effects of these applications on success and performance are indicated by using the "+" sign in the "innovative-digital applications in participation banks and the benefits of these applications" table; the features not included in the participation banks ' web pages or not found in the framed news are left blank in that area. Leaving that field blank does not mean that the participation bank does not have these features/applications, but only shows that it is not among the 150 news stories framed.

\section{Research Findings}

As a result of the scanning the news in the national press about digital applications in participation banking in 2019 and the review of the websites of 6 participation banks in Turkey and the innovative-digital applications of participation banks and the effects of these applications on the success-performance indicators of participation banks are as shown in Table 1. 
Table 1: The Innovative-Digital Applications of Participation Banks and the Effects of These Applications

\begin{tabular}{|c|c|c|c|c|c|c|}
\hline Innovative Digital Applications & 1 & 2 & 3 & 4 & 5 & 6 \\
\hline Artificial intelligence & + & + & & & & \\
\hline Robot (Process) Technologies & + & + & & & & \\
\hline Data Analytics and Big Data Solutions & + & & & & & \\
\hline Innovative ATM and Customer Interface & + & + & & & & + \\
\hline Fintech Start-Up & + & + & & & + & + \\
\hline Placement on the Blockchain Supported BIGA & + & + & & + & & \\
\hline Chatbot / Chat Simulator & & & & + & & \\
\hline Mobile Assistant / Application / Mobile Branch & + & & & + & + & + \\
\hline API Market & & + & & & & \\
\hline Biometrics / Biometric signature & + & & & & & \\
\hline Robo-Advisor / Robo Consultant & & + & & & & \\
\hline Cyber Security Systems / Cyber Insurance & + & & & & & \\
\hline Internet / Mobile / Digital Branch Applications & + & + & + & + & + & + \\
\hline Digital Wallet & & & & + & & \\
\hline Digital / Virtual Pos / Smartphone Pos & + & + & & & + & \\
\hline QR Coded Cheques - Withdrawal with QR Code & + & + & + & + & + & + \\
\hline Banking for the Hearing Impaired & + & + & + & + & + & + \\
\hline \multicolumn{7}{|l|}{ Success-Performance Indicators } \\
\hline Performance, Efficiency and Speed Boost & + & + & + & + & + & + \\
\hline Reduce Cost & + & + & + & + & + & + \\
\hline Saving Time & + & + & + & + & + & + \\
\hline Creating a Technology Oriented Structure & + & + & + & + & + & + \\
\hline Flexibility and Responsiveness to Customers & + & + & + & + & + & + \\
\hline Customer Growth & + & + & + & + & + & + \\
\hline Effective Customer Relationship Management & & + & & + & & \\
\hline Increase in Branding Value & + & + & + & + & + & + \\
\hline Increase in Confidence & + & + & & + & & \\
\hline Growth / Branch Increase & + & + & & & & \\
\hline
\end{tabular}

${ }^{1}$ Albaraka Türk ${ }^{2}$ Kuveyt Türk ${ }^{3}$ Emlak Katılım ${ }^{4}$ Ziraat Katılım ${ }^{5}$ Vaklf Katılım ${ }^{6}$ Türkiye Finans Katılım

\section{Conclusion}

At the end of the study, it has been revealed that digitalization and innovative products and services offered to customers contribute to the formation of a technology-oriented structure, decrease the costs of participation banks, increase their performance and customers, save time with speed increase and increase the branding value. From this conclusion, the proposals that are considered to be useful in the scope of digitalization for our country, which has made an increasing development in the field of participation banking since the 1980s, are as follows:

- Participation banks need to consider innovation, mobile financial technologies and digitalization as a natural component in all their processes, and focus on developing new artificial intelligence-based products such as digital, blockchain, API Market, chatbot. Accordingly, participation banks should prepare digital transformation plans and programs and focus on data mining / information management and smart automation.

- R\&D centers to develop new generation payment systems such as contactless payment and virtual / mobile wallet should be established and investments should be made accordingly. 
- Existing products and services should be moved to digital environment and customer requests should be responded more quickly. In this period, where digitalization continues rapidly, customer satisfaction should be given more importance than ever by increasing product and service diversification.

- More precautions should be taken for information and transaction security, and preventive tools / practices should be developed for this purpose.

Based on the results of the study and the suggestions that are thought to be useful for our country in the field of participation banking within the scope of digitalization, the model named Digital Banking Habitat in Turkey's Participation Banking in Figure 1 has been created.

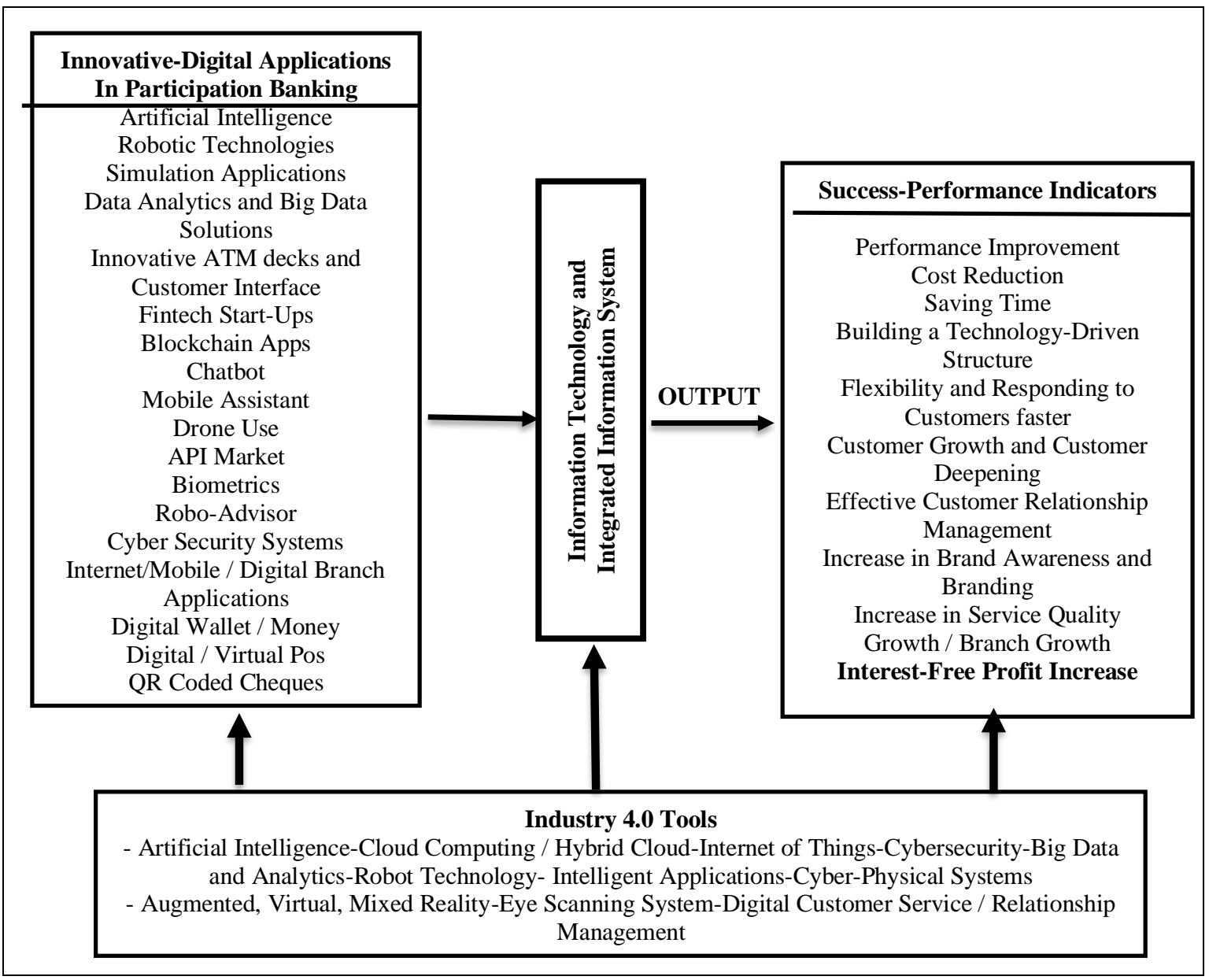

Figure 1: Digital Banking Habitat in Turkey's Participation Banking

Keywords: Management and Strategy, Participation Banking, Digitalisation, Innovation, Content Analysis

Öz: Bankaların müşterilerine inovatif ve hızlı hizmet sunmalarında hayatı kolaylaştırıcı bir araç olan dijitalleşme, Endüstri 4.0 çağında faizsiz finans sektörünün bir aktörü olan katılım bankacılığını da yakından ilgilendirmektedir. API marketler, siber güvenlik, veri analitiği ve big data çözümler, yapay zekaya dayalı chatbot'lar ve blockchain uygulamaları, bulut teknolojiler, arttırılmış ve sanal gerçeklik katılım bankalarının bu dijitalleşme yolculuğundaki en önemli konularındandır. Bu sebeptendir ki çalışmanın amacı, katılım bankacılığında inovatif dijital çözümlerin hangi teknoloji uygulamalarına dayandığının saptanması, Türkiye' deki katılım bankalarına ve onların müşterilerine hangi avantajların sağladığının ortaya çıkarılmasıdır. Bu amaçla 2019 yılındaki ulusal basında yer alan haberler Google arama motorunda taranmış "Faizsiz Finans 
Bankacılığında İnovasyon”, "Katılım Bankacılığı ve Dijitalleşme” ifadelerini içeren çalışma amacına uygun 150 haber çerçevelenmiş, haber içeriklerinde en fazla adı geçen, inovatif/dijital ürün, hizmet ve platformlara yatırımlar yaparak teknolojik altyapısını dijital kanallara taşıyan Türkiye'deki 6 bankanın (Albaraka Türk, Kuveyt Türk, Türkiye Emlak Katılım, Ziraat Katılım, Vakıf Katılım, Türkiye Finans Katılım) web siteleri incelenerek, nitel araştırma yöntemi olan içerik analizi yapılmıştır. Çalışmanın literatür kısmında katılım bankacılığında yenilikçi dijital uygulamalar ile alakalı makalelerden faydalanılmış; mevcut durum tespiti/check-up yapılmış, Türkiye'deki katılım bankalarından seçilmiş inovatif-dijital iyi uygulama örnekleri verilmiş ve içerik analizinden elde edilen bulgulardan hareketle ve katılım bankacılığ alanında ülkemiz için dijitalleşme kapsamında yararlı olacağı düşünülen önerilerden yola çıkılarak, Türkiye'nin Katılım Bankacılığında Dijital Bankacılık Habitatı adlı model oluşturulmuştur. Çalışmanın sonucunda, katılım bankalarının yenilikçi dijital uygulamalarının Yapay Zekâ, Bulut Teknoloji gibi teknoloji kullanımlarını içerdiği ve internet/mobil/dijital bankacılık işlemlerinin arttığı görülmüştür. Sayılan bu uygulamaların marka değeri yarattığı, müşterilerle daha iyi iletişim kurulabildiği, müşteri beklentilerini karşıladığı, performans ve verimlilik artışına yol açtığı, müşterilere hızlı yanıt verebilme olanağı sunduğu, zaman tasarrufu sağladığı, farklı, kaliteli, yenilikçi, hızlı hizmet ile rekabet gücünü ve müşteri sayısını arttırdığı görülmüştür.

Anahtar Kelimeler: Yönetim ve Strateji, Katılım Bankacılığı, Dijitalleşme, İnovasyon, İçerik Analizi

\section{Giriş}

İslami Bankac1lık (Islamic Banking) ve Faizsiz Bankac1lık (Interest-free Banking) olarak da bilinen, İslami kuralları gözeterek işlem yapan Katılım Bankacılığı (Participation Banking), birikimlerini finans alanında faizsiz şekilde değerlendirmek isteyen ve özellikle dini duyarlılığı olan Müslüman yatırımcılar tarafından tercih edilen; Suudi Arabistan, Birleşik Arap Emirlikleri, Katar, Bahreyn, Malezya, Kuveyt, Endonezya, Dubai, gibi ülkelerin liderliğinde gelişim gösteren bir bankacılık modelidir. Buradan hareketle çalışmada aşağıda sıralanan sorulara cevap aranmıştır:

- Türkiye'deki Katılım Bankaları hangi inovatif dijital uygulamaları kullanmaktadırlar?

- Katılım Bankalarınca kullanılan inovatif dijital uygulamaların faydaları nelerdir?

Katılım Bankacılığında inovatif ve dijital uygulamaların tespit edilmesine ve katılım bankacılığındaki bu uygulamaların hangi performans ya da başarı göstergelerine sahip olduğuna dair çok fazla akademik çalışma yapılmamış olması ve yapılan çalışmaların da yüzeysel olarak bu konuyu işlemiş olmalarından dolayı bu çalışmaya ihtiyaç duyulmuş ve çalışmayı özgün hale getirmiş̧tir.

\section{Kavramsal Çerçeve}

Çalışmanın bu kısmında katılım bankacılığı konusuna ve katılım bankalarındaki inovatifdijital uygulama örneklerine yer verilmiştir.

\section{Katılım Bankacılığı ve Katılım Bankalarının Amaçları}

Katılım bankacılığı, bankacılık işlemlerin tümünün faiz olmadan ve riskli spekülatif yapıdan uzak bir şekilde cari ve katılma hesapları aracılığıyla kredi kullandıran, fon toplayan kâr ve zararın öz sermayeye bağlı kalınarak adil bir şekilde dağıtıldığı bir bankacılık modelidir. Bu modelde bankalar, müşterilerinden topladıkları USD, EUR ve TL bazında topladıkları fonları, faizsiz finansman kuralları çerçevesinde sanayi ve ticaret alanında (sanayinin ve ticaretin ihtiyacı olan mamul, yarı mamul veya hammadde, makine, teçhizat, gayrimenkul bu yöntem aracıllı̆ıyla sağlanır) değerlendirilmesi sonucunda meydana gelen kar ve zararı müşterileriyle paylaşırlar, şans oyunları, silah, alkol, tütün gibi sağlığa zararlı olan ürünler katılım bankacılık işlemine konu olamaz. Buradaki altın kural, fonun faiz yerine kar veya zarara katılım yoluyla toplanması ve müşterinin ihtiyacı olan malı satıcıdan peşin alıp o müşteriye vadeli satmak yoluyla (murabaha) veya ortaklık, kiralama yöntemleriyle fon kullandırma yöntemi olan faizsizlik prensibidir (www.ttbb.org.tr, 2019). Türkiye'de ve dünyada halkın belli kesimi, faiz geliri istememektedir. Bu sebepten normal bankalara 
gitmeyen fonlar değerlendirilememekte âtıl kalmaktadır. Bu durum hem ekonomi hem de tasarruf sahipleri açısından kayıptır. Katılım bankaları uyguladıkları faizsizlik sistemiyle bu atıllığın önüne geçmektedir. Katılım bankaları aynı zamanda, mali sistemden yeterli finansman desteği alamayan çok sayıdaki küçük orta büyüklükteki işletmeye de finansal kiralama yoluyla uygun şartlarda yatırım malları temin etmek yoluyla üretimin ve istihdamın artışına, dış ticarete katkı sağlamaktadır. Diğer tüm bankalar Türkiye Bankalar Birliği’ne (TBB) üye olmak zorundayken; katılım bankaları Türkiye Katılım Bankaları Birliği (TKBB) üyesidir. Türkiye'de halen faaliyet gösteren katılım bankaları sırasıyla, Albaraka Türk Katılım Bankası, Emlak Katılım Bankası, Finans Katılım Bankası, Kuveyt Türk Katılım Bankası, Vakıf Katılım Bankası, Ziraat Katılım Bankasıdır (Vurucu ve Arı, 2014: 49).

Faizsiz banka ilk olarak Ahmed En-Naccar liderliğinde 1963 senesinde kurulmuş ve yalnızca dört yıl faaliyetlerini devam ettirebilmiş 1967 senesinde kapanmışıtır. Bu deneme başarısız olsa da sonra kurulacak olan diğer faizsiz bankalara bir nevi öncülük etmiştir (Şekeroğlu ve Özer, 2017: 17). Katılım bankalarının Türkiye'de faaliyet göstermesine izin verilmesi, Resmî Gazete'nin 19 Aralık 1983 tarih ve 18256 sayısında, Bakanlar Kurulu'nun 83/7506 sayılı kararı ile katılım bankalarının çalışmaları büyük ölçüde diğer bankaların çalışma şartları hükümlerine tabi tutulmuştur (Takan ve Boyacıoğlu, 2011: 13). Katılım bankalarının amaçları aşağıda sıralandığı gibidir:

- İslami prensiplerin ekonomik yaşama uygulanması,

- Tasarrufları doğrudan yatırımlara yönlendirerek istihdam yaratma,

- Dengeli bir finans sistemi kurmak,

- Bankacılık işlem ve hizmetlerinin İslami ilkeler doğrultusunda yapılmasını sağlamak,

- Diğer bankalarla birlikte yaşayabilmek, başarı için kar firsatlarından yararlanmak.

\section{Katılım Bankacılığındaki İnovatif ve Dijital Uygulamalar}

Dijitalleşme, organizasyonların kaynaklarını kullanarak, büyüme, gelir ve organizasyona değer katacak firsatlara dönüştürme faaliyetleri olarak ifade edilir. Başka bir ifade ile dijitalleşme, organizasyonun iş gücü, bilgi ve teknoloji kaynaklarını birleştirerek, farklı müşteri deneyimleri oluşturmak, yeni iş modelleri geliştirmek, ürün ve hizmetlerde yeniliği olanaklı kılmak ve organizasyonun kaynaklarını daha etkin ve verimli bir şekilde kullanmak için teknolojiyi bu kaynaklara adapte etmektir (Mert, 2020: 51). Dijitalleşme, klasik bankalarda olduğu gibi katılım bankacılığında da müşteriler için kişisel uygulamalardan, organizasyon biçiminden, iş süreçlerine ve iş modeli tasarımlarına kadar farklı sahalarda kendini göstermektedir. Bankacılığın olmazsa olmazı, finansal hizmetleri değişime uğratan/uğratacak teknolojilerden birkaçı aşağıdaki gibi sıralanmıştır (fintechistanbul.org, 2019):

- Blockchain: Blockchain para, değerli kâğıt ve kimlik gibi değer ifade eden verilerin güvenli şekilde depolanmasına ve yönetilmesine olanak sağlayan dijital kayıt teknolojisidir. $\mathrm{Bu}$ kayıtlar herkese açık, sıralı, zaman damgalı, dağıtık ve şeffaftır. Blockchain'in finansal araçlar, kamusal kayıtlar, özel kayıtlar, fiziksel varlık kilitleri, soyut varlıklar olmak üzere pek çok kullanım alanı bulunmaktadır. Blockchain'in finans sektöründe kullanımına ilişkin örnekleri arasında Ethereum, Bitcoin, Ripple, Everledger ve Hyperledger sayılabilir (Türkmen ve Durbilmez, 2019: 31-34).

- FinTech: Finansal teknoloji ve yenilikleri ifade eden FinTech, parasal işlemlerin daha hızlı ve kaliteli yapılmasını sağlamaktadır. İslami bankacılığa talebin arttığı bu dönemde FinTech inovasyonları Türkiye gibi gelişmekte olan ülkelerdeki katılım bankalarına müşteri sayısını ve tabanını genişletmeye ve ürün/hizmet çeşitliliğini arttırmaya yönelik büyük firsatlar sunmaktadır. Dijital birikim yönetimi, dijital teşvik, kişilerarası ödemeye dayalı inovasyonlar, KOBİ ve denk kredi platformları, FinTech'in katılım bankacıllı̆̆ndaki 
uygulama alanlarından yalnızca birkaçıdır (katilimfinansdergisi.com, 2019). Bunlara ek olarak FinTech inovasyonları dijital ve mobil ödeme, finansal platform, kişisel finansal yönetim, blockchain teknolojiler, para piyasaları ve yatırım, çok fazla kaynak kullan müşteri kazanımı ve ciro artışı gibi çözümler sunmaktadır.

- API Platformları (Application Programming Interface-Uygulama Programlama Arabirimi): Bir uygulama/servisin (Facebook, Google, Yourube, Android vb.) yeteneklerinin dışarıdan izin verildiği oranda kullanılabilmesini; bir yazılımın diğer yazılımla iletişime geçmesini sağlayan ara yüzdür. Bu sistem Fintech geliştiricilerin ve yeni bir sistem kurmak isteyen girişimcilerin pek çok veri ve bilgiyi hazır olarak almasına, daha az maliyetle daha kısa bir sürede hizmet sunmasına imkân tanır. Birden fazla kredi kartı ve banka hesabı bulunan müşterilerine bankalar, API ara yüzleri ile ulaşarak FinTech uygulaması üzerinden kişilerin tüketim alışkanlıklarına göre kişisel bütçeleme yapabilir; satın almak isteyecekleri bir ürün için her ay ne miktarda para biriktirmeleri gerektiğini söyleyebilirler (fintechistanbul.org, 2019).

- Robotik Süreç Otomasyonu/Teknolojileri: Dijital dönüşüm aracı, yapay zekanın bir parçası olan robotik süreç otomasyonu, makine öğrenmesine dayalı e-posta kontrolü, personel bilgi girişleri ve raporlama, API'ler ile etkileşime girip hesap yapma, fatura kesme gibi pek çok işi yapabilen, 7/24 çalışma imkânı olan hata ve riski sıfıra indirebilen teknolojinin adıdır (Özsoy, 2019).

- Yapay Zekâ: Yapay zekâ, yapay araçlardan oluşan, insan gibi davranışlar sergileyebilen, insana ihtiyaç duymaksızın otonom olarak işleyen, insanların pek çok bilişsel yeteneğini kestirebilen, bazılarını tamamen otomatik hale getirebilen, bilgisayar zekâsı ile nöroloji biliminin ortak birleşiminden meydana gelen programlardır. Yapay zekâ, insan beyninin çalışma şeklinin, insana özgü bilgi sağlama, algılama, görme, karar verme gibi özelliklerin akıllı bilgisayar programları aracılığıyla simüle edilmesi ve akıllı teknolojilere, robotik makinelere aktarma bilimidir. Yapay zekâ, hisse senedi, meta ve para alım satımına otomatik kararlar verebilmektedir (Nilsson, 2019: 641).

- Hibrit Bulut: Hibrit bulut, iki veya daha fazla bulutun (topluluk, özel, genel bulut) birlikte kullanılmasıyla oluşan ve bulutların kendi aralarında veri ve uygulama transfer etmelerine imkân sağlayan bir kurum-yapının internet bağlantısına ihtiyaç duyulmadan yerel ağdan kullanılabilen bulut bilişim modelidir (Kaya, 2017: 17). Hibrit bulut kullanımı hızla yayılmaktadır. Özellikle de büyük bilgi teknolojisi alt yapısına sahip bankalar, sanal ortamda yapay zekâ destekli uygulamalarla müşterilerine esnek, güvenli ve daha az maliyetle deneyimler sunabiliyorlar (www.sanliturk.com, 2019).

- Arttırılmış, Sanal ve Karışık Gerçeklik: Artırılmış gerçeklik/Augmented Reality (AR), bilgi, video, GPS gibi sinyal/girdilerle arttırılan gerçek/fiziksel bir ortamın ekran seti gibi ekipmanlarla canlı olarak görüntüsünün sunulduğu sistemin adıdır. Artırılmış gerçeklikte, kullanıcı doğal ortamda kayıtlı 3D nesneleri görüntüleyerek gerçek ve bilgisayarın ürettiği nesnelerle etkileşime girer (Demirezen, 2019: 3). Sanal gerçeklik/ Virtual Reality (VR), akı1lı telefon ya da başa takılan ekran (HMD) cihazlarla oynatılabilen bilgisayar tabanlı simülasyon ortamıdır. Karışık gerçeklik/Mixed Reality (MR) ise sanal ve gerçek dünyaların birleştiği; dijital ve fiziksel bileşenlerin gerçek zamanlı olarak etkileşime girdiği ortamdır (bimteknoloji.com, 2019). Bankalarda gerçekleştirilen işlemlerin akıllı telefonlara ve internete taşınması, ses tanıma teknolojisindeki gelişmeler ve ilerlemeler, sesli dijital 
asistanların varlığı bankaların müşterilerle uzaktan işlem yapabilmelerine olanak sağlamış; yapay zekalı chatbot'lar hayatımıza girmiştir. Sanal, Artırılmış ve Karışık gerçeklik uygulamaları bankalar tarafından müşterilerine en yakın şubeleri ve ATM'leri bulmaları amacıyla kullanılmaktadır. Sanal ve artırılmış gerçeklik uygulamasıyla yatırım danışmanlığ hizmeti verilebilir hesap açı1ışları ve kredi başvuruları daha az zamanda ve daha az maliyetle yapılabilir (fintecistanbul.org, 2019).

- Siber Güvenlik: Bankalar kendilerine, müşterilerine, kamu kurum ve kuruluşlarına ait kişisel, gizli bilgileri bilişim araçları yoluyla saklamaktadır. Bankacılıkla ilgili pek çok işlem e-ödeme/cep telefonu/mobil araçlar ile yapılmakta böylelikle de internet dünyasında siber saldırılara maruz kalınmaktadır. Bu sebeptendir ki bankacılık sektöründe müşteri güveni sağlayabilmede ve verileri koruyabilmede siber güvenlik risklerinin minimize edilmesi hatta ortadan kaldırılması büyük önem arz etmektedir. Dijital çağda bankalar, siber saldırılara karşı önlemler almalı, güvenlik altyapılarına daha fazla yatırım yapmalıdır (Yeşilyurt, 2015: 99). Türkiye'deki bankaların güvenlikle ilgili önlemleri şöyle sıralanabilir (arkakapidergi.com, 2019):

$>$ Ek parola tanımlama

$>$ Rakam ve harflerden oluşan 12 karakterli parola kullandırtma

$>$ Şifre üreticisi

$>$ Mobil imza

$>$ SMS şifresi isteme

$>$ IP adresi veya ISS tanımlamak

$>$ Giriş sonrasında gizli veri doğrulaması yapma

$>$ Yalnızca T zamanında giriş yapılması/saat ve tarih kısıtlaması

$>$ Bilgilendirme SMS'i

$>$ Alıc1 White-List'i tanımlama

- Biometrics/Biyometri: Biyometrik imza, kişinin fiziksel (yüz, göz, göz damarı, iris, parmak damarı, parmak izi, ses) ve davranışsal (tuşa basma hareketi, imza analizi) spesifik özelliklerini tanıyarak kimlik tespitinin bilgisayar destekli sistemle yapılmasıdır. Başka bir tanımla Biyometrik imza, dijital kalem kullanılarak tablet/akıllı telefon üzerinde atılan taklit edilemeyen, kişiye özel, basınç, hız, ivme ve eğim gibi verilerin birleşmesiyle oluşan imzadır. Bankacılıkta dijital dönüşümde biyometrik imza zaman tasarrufu sağlaması, çevreci olması, maliyet avantajı ve dijitalleşme adına marka değeri sağlaması açısından önem taşımaktadır (www.secube.com, 2019).

Türkiye'deki katılım bankalarının inovatif ve dijital uygulama örnekleri aşağıda Tablo 1'de özetlendiği gibidir.

Tablo 1: Katılım Bankalarının İnovatif ve Dijital Uygulama Örnekleri

\begin{tabular}{|c|c|}
\hline $\begin{array}{l}\text { Türkiyedeki } \\
\text { Katılım } \\
\text { Bankaları }\end{array}$ & $\begin{array}{l}\text { Seçilmiş İnovatif-Dijital } \\
\text { İyi Uygulama Örnekleri }\end{array}$ \\
\hline $\begin{array}{l}\text { Albaraka } \\
\text { Türk }\end{array}$ & $\begin{array}{l}\text {-Insha (Avrupa'nın İslami İlk Dijital Bankası): Faizsiz şubesiz ve fiziksel evraksız } \\
\text { dijital bankacılık platformudur. Hem IOS hem de Android platformları için ücretsiz } \\
\text { kullanım sağlamaktadır. Insha, dünyanın ilk ve tek BAAS (Banking As A Service) } \\
\text { bankası olan Solarisbank'ın bankacıllık lisansını ve altyapısını kullanmak suretiyle } \\
\text { modüler bir yapı içinde kıta Avrupa'sında katılım bankacilığı hizmetleri sunmaktadır. }\end{array}$ \\
\hline
\end{tabular}

Turkish Studies - Economy, 15(3) 
-Robotik Süreç Otomasyonu: Manuel ve birbirinin tekrarı ve öngörülebilen tüm işleri yazılım robotları yapmaktadır.

-Inooster: Oyunlaştırma ve Performans Yönetim Programı

-Techsign (Biyometrik Imza): Müşterilerin akıllı ekran ya da tabletler üzerinden bir kalemle hızlı şekilde imzalama işlemini gerçekleştirdiği biyometrik uygulamadır. -Albaraka Mobil: Yüz Tanıma Teknolojisi, QR Kod ile Para Çekme, Albaraka Asistan -Albaraka Keşfet Programı: Kurum içinde girişimcilik ve inovasyon ruhunu yaymak, yönetim ile çalışanların etkileşimini artırmak, çalışanları inovasyon süreçlerine dâhil edip tasarım odaklı düşünme gibi yöntemlerle inovasyon yapma yeteneklerini artırmak. -Albaraka Garaj: Yeni teknolojileri öğrenmek, test etmek, startuplarla iş birliği geliştirmek, hızlı inovasyon döngüleri yaratabilmek ve banka dışındaki inovasyon ve girişimcilik atmosferini içeri taşımak, teknoloji tabanlı finans alanına özgü proje ve iş fikirlerini kuluçka ve hızlandırma imkânları ile kurum içi PoC (Proof of Concept) çalışmaları desteklemek için kurulmuştur.

-Alneo: Alneo, Dijital bankacılık uyumunu artıran ve zaman-mekân sorununu ortadan kaldıran, işletmelerin POS masrafı vermediği kullanıcıların SMS ve QR kod ile doğrudan ödeme alabileceği, müşterilerin ise Alneo Cüzdan ile dilediği kredi kartından alışveriş yapabilmelerine olanak sağlayan Türkiye'nin ilk yapay zekâ destekli hızlı ve kolay ödeme platformudur.

-Nöbetçi Transfer: İnternet şubesi veya Mobil Platform üzerinden Nöbetçi Transfer uygulaması ile müşteriler, zaman kısıtı olmaksızın dilediği yerde EFT işlemlerini yapabileceklerdir.

Türkiye Mobil şube ve internetle döviz alım satımı yapabilme, hesap açabilme, yurtiçine ve yurt Emlak dişına döviz ve TL cinsinden para transferi yapabilme, fatura ödeme gibi hayatı Katılım kolaylaştırıcı çözümler sunan Emlak Katılımla 7/24 bankacılık işlemleri yapilabilmektedir.

Türkiye - TFX TARGET Platformu: 5×24 yatırım işlemi yapılabilen döviz, kıymetli maden alış
Finans satış platformun mobile taşındığı bir uygulamadır. Müşteriler bu uygulama sayesinde Katılım anlık kur hareketleri hızlıca ve kolayca takip edebilmektedir.

-Engelsiz Bankacılık: İşitme engeli ve 70 yaş üstü müşterilerin mobil şube ya da internet aracılığıyla 7/24 Canlı Destek alarak Müşteri İletişim Merkezi ile chat yapmalarına olanak sağlayan hizmettir.

Kuveyt Türk $\quad$-Faizsiz Dijital Katılım Bankacılı̆̆ Platformu: Senin Bankan

-XTM: Müşterilerin dijital cihaz aracılığıyla çağrı merkezi yetkilisiyle görüntülü bağlantı gerçekleştirerek bankacılık işlemlerini hızlı bir şekilde yapmasını sağlar.

-Cebim POS: Bankacılık sektörünün telefonları POS'a dönüşmesini sağlayan ilk akıllı telefon uygulamasıdır. Bütün akıllı cep telefonlarını destekleyen, herhangi bir bankanın bütün banka ve kredi kartlarından ödeme yapılabilmesini pratik ve güvenli bir şekilde sağlamaktadır. Cebim POS'ta kullanım, kurulum, bakım ve cihaz gibi ücretler bulunmadığından esnafın ve KOBİ'lerin tahsilat masrafları büyük ölçüde azalmaktadır. -Robot Süreç Otomasyonu: Manuel ve birbirinin tekrarı ve öngörülebilen tüm işleri yazılım robotları yapmaktadir.

-API(Application Programming Interface-Uygulama Programlama Arabirimi) Market: $\mathrm{Bu}$ sistem Fintech geliştiricilerin ve yeni bir sistem kurmak isteyen girişimcilerin pek çok veri ve bilgiyi hazır olarak almasına, daha az maliyetle daha kısa bir sürede hizmet sunmasına imkân tanır.

-İşitme Dili Bankacllığl: Kuveyt Türk, XTM'nin görüntülü iletişim özelliğini işitme engelli bireyler için kullanışlı ve pozitif değere dönüştürmüştür. İşitme engelli kullanıcılar, XTM şubelerinden tek tuşla görüntülü olarak çağn merkezlerine bağlandıklarında onlara işaret dilini bilen bir uzman çıkmakta ve bu sayede işlemler kolayca ve rahatlıkla gerçekleştirebilmektedirler.

-Mufi Uygulamasi: Kullanıcılar tarafindan faturalarının tek uygulama üzerinden takip edilmesine ve ödeme işlemlerinin yapılmasına imkân sağlayan ödeme platformudur.

Vakıf Katılım $\quad$-Fintech (Finansal Teknoloji Şirketleri): Birer inovasyon merkezi işlevi görmektedir. Yeni nesil ödeme sistemleri ve dijital olarak hizmet sunma, ortak platform oluşturma 
fintech ile iş birliği ile yapılmaktadır. Fintech para transferi, ödeme hizmetleri, altyapı sunucuları yönünden işlem hızı ve kolaylığı sağlamaktadır.

-VFX Online Katılım: 5/24 işlem yapma imkânı sağlayan döviz alış satış platformudur. -Sanal POS: İş gereksinimlerini karşılamada hızlı yönetim hedefiyle, güncel teknolojiye sahip ana bankacılık sistemi ile entegrasyonu sağlanmış akıllı bir uygulamadır.

Ziraat -Katılım Mobil /Mobil Finasman: Acil finansa ihtiyaç duyulduğu zaman bankaya Katılım gitmeden Katılım Mobile girerek finansman talebi oluşturmaya, finansman işlemini hızlıca tamamlamaya imkân sağlar. Müșterilerin 7/24 iletişim kurabileceği Canlı Cevap uygulaması Katılım Mobil'e eklenmiş böylece müşteri memnuniyetinin sağlanmasıyla internet bankacılığı kullanan müşteri sayısı yüzde yüz artmıştır.

-Ziraat Asistan: Yerli chatbot teknolojisi sanal web asistanı olan ziraat asistan, doğal dil işleme teknolojisi yoluyla müşterilerin bankacılık işlemleri hakkındaki sorularını cevaplayarak onlara gelişmiş self-servis deneyimi sunmaktadır.

\section{Yöntem}

"Faizsiz Finans Bankacılığında İnovasyon", "Katılım Bankacılığ1 ve Dijitalleşme” ifadeleri Google arama motorunda taranmış ve araştırmanın amaciyla örtüşen 150 haber/makale çerçevelenmiş haber içeriklerinde en fazla adı geçen, inovatif/dijital ürün, hizmet ve platformlara yatırımlar yaparak teknolojik altyapısını dijital kanallara taşıyan Türkiye'deki 6 bankanın (Albaraka Türk, Kuveyt Türk, Türkiye Emlak Katılım, Ziraat Katılım, Vakıf Katılım, Türkiye Finans Katılım) web siteleri incelenerek içerik analizi yapılmıştır. Dolayısıyla Albaraka Türk, Kuveyt Türk, Türkiye Emlak Katılım, Ziraat Katılım, Vakıf Katılım, Türkiye Finans Katılım Bankaları araştırmanın örneklemini oluşturmuştur. "Katılım Bankalarında İnovatif-Dijital Uygulamalar ve $\mathrm{Bu}$ Uygulamaların Faydaları" tablosunda internet taraması sonucunda katılım bankalarının müşterilerine sunmuş olduğu inovatif-dijital uygulamalar ve bu uygulamaların başarı ve performansa etkilerinden var olanlar "+" işareti kullanılarak belirtilmiş; gerek katılım bankalarının web sayfalarında yer almayan gerekse de çerçevelenmiş haberlerde rastlanmayan özellikler o alanda boş bırakılmıştır ve o alanın boş bırakılması katılım bankasında bu özelliklerin/uygulamaların olmadığı anlamına gelmemekte olup yalnızca çerçevelenen 150 haber arasında olmadığını göstermektedir.

\section{Bulgular}

2019 yılındaki katılım bankacılığındaki dijital uygulamalarla ilgili ulusal basında yer alan haberlerin taranmasından ve Türkiye'deki 6 katılım bankasının (Albaraka Türk, Kuveyt Türk, Türkiye Emlak Katılım, Ziraat Katılım, Vakıf Katılım, Türkiye Finans Katılım) web sitelerinin incelenmesinden ortaya çıkan katılım bankalarının inovatif-dijital uygulamaları ve bu uygulamaların katılım bankalarının başarı-performans göstergelerine etkileri Tablo 2'de gösterildiği gibidir. 
Tablo 2: Katılım Bankalarında İnovatif-Dijital Uygulamalar ve Bu Uygulamaların Faydaları

\begin{tabular}{|c|c|c|c|c|c|c|}
\hline İnovatif Dijital Uygulamalar & 1 & 2 & 3 & 4 & 5 & 6 \\
\hline Yapay Zekâ & + & + & & & & \\
\hline Robot (Süreç)Teknolojileri & + & + & & & & \\
\hline Veri Analitiği ve Big Data Çözümler & + & & & & & \\
\hline Yenilikçi ATM ve Müşteri Ara Yüzü & + & + & & & & + \\
\hline Fintech Start-Up & + & + & & & + & + \\
\hline Blockchain Destekli BIGA Platformda Yer Alma & + & + & & + & & \\
\hline Chatbot/Sohbet Simülatörü & & & & + & & \\
\hline Mobil Asistan/ Uygulama/Mobil Şube & + & & & + & + & + \\
\hline API Market & & + & & & & \\
\hline Biometrics/Biyometrik imza & + & & & & & \\
\hline Robo-Advisor/Robo Danışman & & + & & & & \\
\hline Siber Güvenlik Sistemleri/Siber Sigorta & + & & & & & \\
\hline İnternet/Mobil/Dijital Şube Uygulamaları & + & + & + & + & + & + \\
\hline Dijital Cüzdan & & & & + & & \\
\hline Dijital/Sanal Pos/Akıllı Telefon Pos & + & + & & & + & \\
\hline Karekodlu Çek-QR Kodla Para Çekme & + & + & + & + & + & + \\
\hline İşitme Dili Bankacılığı/Engelsiz Bankacılık & + & + & + & + & + & + \\
\hline \multicolumn{7}{|l|}{ Başart-Performans Göstergeleri } \\
\hline Performans, Verimlilik ve Hız Artı̧̧1 & + & + & + & + & + & + \\
\hline Maliyeti Düşürme & + & + & + & + & + & + \\
\hline Zaman Tasarrufu Sağlama & + & + & + & + & + & + \\
\hline Teknoloji Odaklı Bir Yap1 Oluşturma & + & + & + & + & + & + \\
\hline $\begin{array}{l}\text { Esneklik ve Müşteriye Daha Hızlı Yanıt } \\
\text { Verebilme/İşlem Hızında Artış }\end{array}$ & + & + & + & + & + & + \\
\hline Müşteri Artış1 & + & + & + & + & + & + \\
\hline Etkin Müşteri İlişskileri Yönetimi & & + & & + & & \\
\hline Bilinirlik ve Markalaşma Değerinde Artış & + & + & + & + & + & + \\
\hline Güven Artış1 & + & + & & + & & \\
\hline Büyüme/Şube Artış1 & + & + & & & & \\
\hline
\end{tabular}

${ }^{1}$ Albaraka Türk ${ }^{2}$ Kuveyt Türk ${ }^{3}$ Emlak Katılım ${ }^{4}$ Ziraat Katılım ${ }^{5}$ Vaklf Katılım ${ }^{6}$ Türkiye Finans Katılım

\section{Sonuç}

Çalışma sonunda katılım bankalarının dijitale odaklandığı ve dijitalleşmeyi merkeze aldığı bu günlerde dijitalleşmenin ve müşterilere sunulan inovatif ürün ve hizmetlerin katılım bankalarının maliyetlerini düşürüp performanslarını ve müşterilerini arttırdığı, zaman tasarrufu sağladığı ortaya çıkmıştır. Bu sonuçtan hareketle, katılım bankacılığı alanında 1980'li yıllardan itibaren gittikçe artan bir gelişme kaydetmiş olan ülkemiz için dijitalleşme kapsamında yararlı olacağı düşünülen öneriler şunlardır:

- Katılım Bankalarının inovasyonu, mobil finansal teknolojileri ve dijitalleşmeyi tüm süreçlerinde doğal bir bileşen olarak görmesi dijital, blockchain, API Market, chatbot gibi yapay zekâ tabanlı yeni ürünler geliştirmeye önem vermesi gerekmektedir. Bu doğrultuda da katılım bankaları dijital dönüşüm plan ve programları hazırlamalılar veri madenciliği/bilgi yönetimi ve akıllı otomasyon konularına ağırlık vermelidirler. 
- Temassiz ödeme ve sanal/mobil cüzdan gibi yeni nesil ödeme sistemlerini geliştirmeye yönelik AR-GE merkezleri kurulmalı buna yönelik yatırımlar yapılmalıdır.

- Mevcut ürün, hizmet-servisler dijital ortama taşınmalı müşteri isteklerine daha hızlı cevap verilebilmelidir. Dijitalleşmenin hızla devam ettiği bu dönemde ürün ve hizmet çeşitlendirmesine giderek müşteri tatmini ve memnuniyeti her zamankinden daha fazla önemsenmelidir.

- Bilgi ve işlem güvenliği için daha fazla önlem alınmalı buna yönelik önleyici araçlar/uygulamalar geliştirilmelidir.

Yukarıda sıralanan katılım bankacılığı alanında ülkemiz için dijitalleşme kapsamında yararlı olacağ1 düşünülen önerilerden yola çıkılarak, Şekil 1'deki Türkiye'nin Katılım Bankacıllı̆̆ında Dijital Bankacılık Habitatı adlı model oluşturulmuştur. Modelde yapay zekâ, bulut bilişim/hibrit bulut, nesnelerin interneti, robot teknoloji, siber güvenlik sistemleri gibi Endüstri 4.0 araçlarının katılım bankacılığındaki inovatif-dijital uygulamalara dönüşmesiyle ve bankacılık hizmetleri şeklinde müşterilere sunulmasıyla ve de bankacılıktaki tüm fonksiyonlarla entegre olmuş bilgi teknolojileri ve bütünleşik bilgi sistemiyle birlikte uyumlaştırılmasıyla bankaların başarı-performans göstergelerinde pozitif yönde artış/iyileşme olacaktır. Nitekim bu modeli doğrulayacak çalışmalar da bulunmaktadır. Yetiz ve Ünal'ın (2018) çalışmalarında, inovatif teknolojilerle daha hızlı hale gelen kredi değerlendirme süreçlerinin müşteri kitlesini artırdığı, finans piyasasındaki inovatif ürün ve uygulamaların artmasıyla müşteri sayısının ve rekabet gücünün arttığı, bu artışın da karlılık ve verimlilik artışıyla sonuçlandığ 1 ifade edilmiştir. Menteş (2019) çalışmasında, teknolojik yeniliklerin bankaların müşteri profilini ve gelen talepleri değiştirdiğini, bankacılık sektörünün rekabete direnebilmesinin yolunun teknolojik gelişmelere hızla uyum sağlanmasından ve finansel teknoloji şirketleriyle iş birliği yapılmasından geçtiğini ortaya koymuştur. Shaikh vd. (2017), bankacılık ve finans sektöründeki inovatif müşteri odaklı çözümlerin rekabet üstünlüğü sağladığ 1 ; Chaarani ve Abiad (2018) ise, ATM ve internet bankacılığında gerçekleştirilen teknolojik yeniliklerin karlılığ arttırdığ 1 , rekabet avantajı yarattığ , bankacılık işlemlerini hızlandırdığ 1 , müşterilere zaman tasarrufu sağladığı ve Lübnan Bankalarının performansları üzerinde pozitif katkıları olduğu sonucuna varmışlardır. 


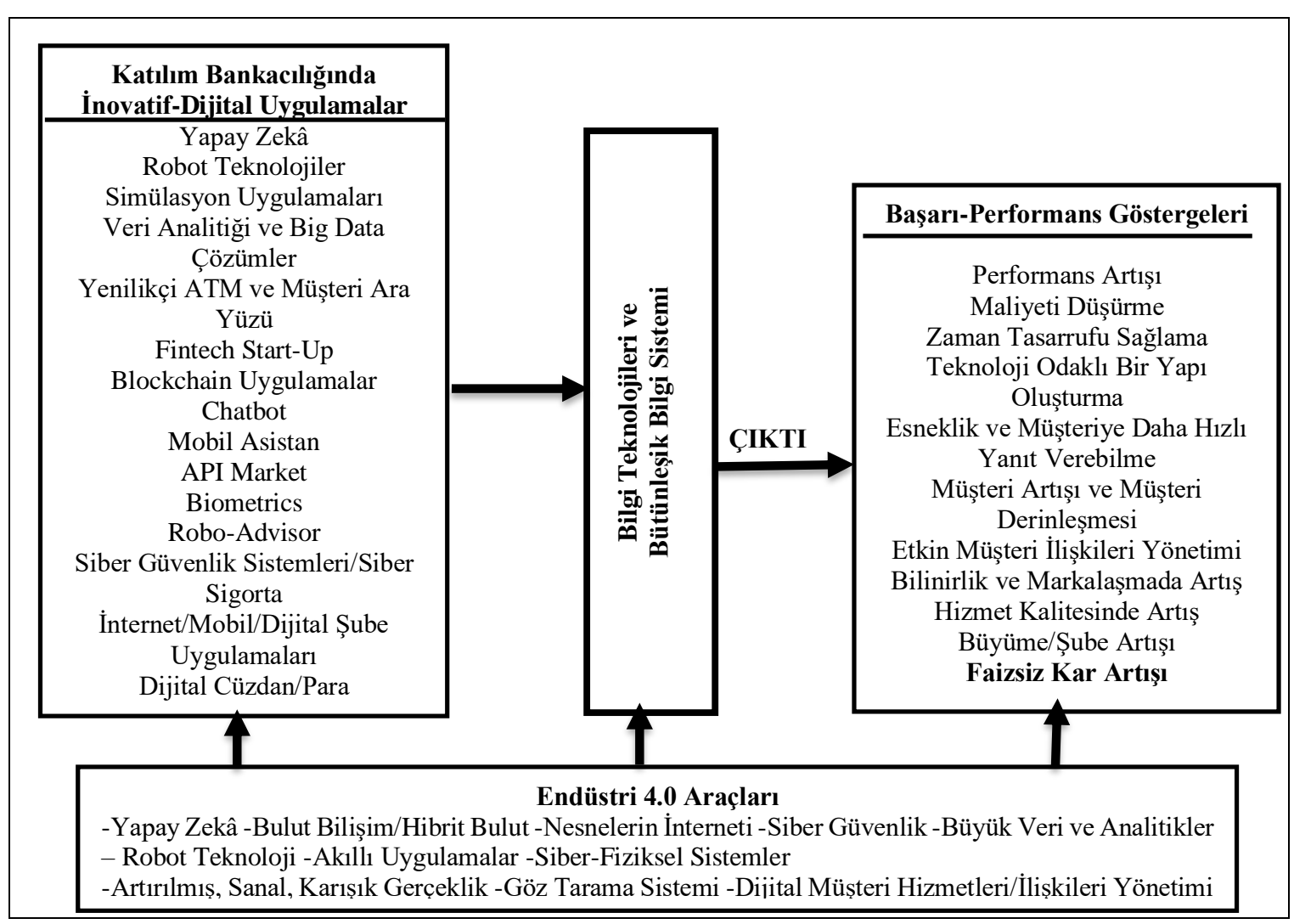

Şekil 1: Türkiye'nin Katılım Bankacılığında Dijital Bankacılık Habitatı

Son olarak çalışmanın kısıtlarından bahsetmek yerinde olur. Bu çalışmanın birinci kısıtı, müşterilerine inovatif-dijital uygulamalar sunan Türkiye'deki katılım bankalarının yalnızca 150 haberin çerçevelenerek, web siteleri incelenerek içerik analizi yapılmasıdır. Mülakat, anket gibi diğer araştırma yöntemlerinin de kullanılmasıyla daha fazla veri toplanabileceği ve daha kapsamlı, net sonuçlar elde edilebileceği düşünülmektedir. Araştırmanın ikinci kısıtı örneklemin Türkiye'deki 6 katılım bankası ile sınırlı kalmasıdır. Araştırmaya dünyadaki diğer katılım bankalarından da ilave edilebilirse örneklem sınırı genişletilebileceği gibi Türkiye ve dünyadaki katılım bankaları detaylı şekilde kıyaslanabilecektir.

\section{Kaynakça}

Arkakapı Dergi (2019). Türkiye'deki bankaların güvenlik yaklaşımları ve kullanım tedbirler, https://arkakapidergi.com, (02.03.2020).

BİM Teknoloji (2019). Karışık gerçeklik ve BİM, https://www.bimteknoloji.com, 02.03.2020.

Chaarani, H, ve Abiad, Z. (2018). The impact of technological innovation on bank performance, Journal of Internet Banking and Commerce, 23(3): 1-33.

Demirezen, B. (2019). Artırılmış gerçeklik ve sanal gerçeklik teknolojisinin turizm sektöründe kullanılabilirliği üzerine bir literatür taraması, Uluslararası Turizm Araştırmaları Dergisi, 3 (1): 1-26.

FinTech İstanbul (2017). API nedir? FinTech girişimleri için nedenlidir? https://fintechistanbul.org, 02.03.2020. 
FinTech İstanbul (2018). Gelecek 5 yilda finansal hizmetleri değişime uğratacak 10 teknoloji” https://fintechistanbul.org, 03.03.2020.

Kaya, F. (2017). İller Bankası Anonim Şirketi bulut bilişimim uygulamaları ve İller Bankası'na uygulanabilirliği. İlbank, Uzmanlık Tezi.

Menteş, A. (2019). Bankacıllk sektörüne bir tehdit unsuru olarak finansal teknoloji şirketleri, Balkan ve Yakın Doğu Sosyal Bilimler Dergisi, 5(1): 49-53.

Mert, G. (2020). Kurumların stratejik yönetim süreçlerinde dijitalleşmenin rolü, Journal of Social, Humanities and Administrative, 6(22): 41-58.

Nilsson, N, J. (2019). Yapay Zekâ: Geçmişi ve geleceği (çev. M. Doğan), Boğaziçi Üniversitesi Yayınevi.

Özsoy, Ş. (2019). Robotik süreç otomasyou nedir? ne değildir? https://www.dunya.com, 02.03.2020.

Sanlitürk (2019). Global şirketlerin yüzde 85'ihibrit bulutu seçiyor, https://www.sanliturk.com.tr, 03.03. 2020.

Shaikh, A., Glavee-Geo, R. ve Karjaluoto, H. (2017). Exploring the nexus between financial sector reforms and the emergence of digital banking culture-Evidences from a developing country, Research in International Business and Finance, 42: 1030-1039.

Secube (2019). Gelişmiş elektronik imza uygulamas1, https://www.secube.com.tr, 02.03.2020.

Şekeroğlu, S. ve Özer, K. (2017). Bankacılık sektöründe yükselen değer: Katılım bankacılı̆̆ı. Bankacılık ve Finansal Araştırmalar Dergisi, 4 (2): 15-25.

Takan, M., ve Boyacıoğlu, M. A. (2011). Bankacılık teori, uygulama ve yöntem, Nobel Yayınevi.

Türkiye Katılım Bankaları Birliği. (2016). Katılım bankacılı̆̆ı nedir? Nasıl çalışır? http://www.tkbb.org.tr, 02.03.2020.

Türkmen, S. Y. ve Durbilmez, E. S. (2019). Blockchain teknolojisi ve Türkiye finans sektöründeki durumu, Finans ve Sosyal Araştırmalar Dergisi, 4(1): 30-45.

Vurucu, M., Arı, M.U. (2014). A’dan Z'ye bankacılık, Seçkin Yayıncılık.

Yeşilyurt, H. (2015). Finansal hizmet sektöründe siber güvenlik riskleri ve çözüm yolları: Ödeme sistemleri ve tedarik zinciri bütünlüğü, Celal Bayar Üniversitesi Dergisi, 13 (2): 97-120.

Yetiz, F. ve Ergin, A. Ü. (2018). Finansal yeniliklerin gelişimi ve Türk bankacılık sektörüne etkileri, Kastomonu Üniversitesi İktisadi ve İdari Bilimler Fakültesi Dergisi, 20(4): 117-135. 